\title{
EDUCAÇÃO AMBIENTAL: ENTRE A POÉTICA DOS SABERES POPULARES E A EMERGÊNCIA DO CONHECIMENTO CIENTÍFICO
}

\author{
Entrevista com a Profa. Dra. Michèle Sato (Gepea-UFMT) ${ }^{1}$
}

Yuji Gushiken²

Maria Aparecida de Oliveira ${ }^{3}$

\begin{abstract}
Resumo: Na Universidade Federal de Mato Grosso (UFMT), a professora Michèle Sato lidera o Grupo Pesquisador em Educação Ambiental, Comunicação e Arte (Gepea-UFMT), através do qual tem investigado o tema em nível teórico e empírico no amplo campo da Educação e formado gerações de pesquisadores nos níveis de graduação, mestrado e doutorado. A pesquisadora comenta, nesta entrevista realizada em 2008, a emergência e a consolidação da Educação Ambiental como área do conhecimento, as nuances da interdisciplinaridade, a interface com o campo cultural e os desafios teórico-metodológicos a serem enfrentados nas práticas de ensino, pesquisa e extensão.
\end{abstract}

Palavras-chave: Educação Ambiental; Cultura; Saberes Populares; Ciência.

Abstract: At the Federal University of Mato Grosso (UFMT), Professor Michèle Sato leads the Environmental Education, Communication and Art Research Group (GepeaUFMT), through which she has investigated this topic at epistemological and empirical levels in the broad field of Education and has contributed to the graduation of generations of researchers at undergraduate, master's and doctorate levels. In this interview, conducted in 2008, the researcher comments on the emergence and consolidation of Environmental Education as an area of knowledge, the nuances of interdisciplinarity, the interface with the field of culture and the theoretical and methodological challenges to be faced in teaching, research and extension practices.

Keywords: Environmental Education; Culture; Popular Wisdom; Culture; Science.

\footnotetext{
${ }^{1}$ Entrevista pautada e realizada como prática laboratorial de jornalismo cultural em 2008, ainda inédita, agora publicada como registro da História da Educação Ambiental no Brasil. Recomendamos ao leitor atentar-se à temporalidade da entrevista, às pautas prementes daquela década e às transformações políticas e educacionais no período entre 2008 e 2020 . Nota do Editor: A entrevista inaugura a nova seção "Vozes da REBEA" na RevBEA.

2 Universidade Federal de Mato Grosso. E-mail: yug@uol.com.br.

Currículo Lattes: http://lattes.cnpq.br/4697447223916653

3 Universidade Federal de Mato Grosso E-mail: mariaaolive.oi@gmail.com.

Curriculo Lattes: http://lattes.cnpq.br/4379821419072427
} 

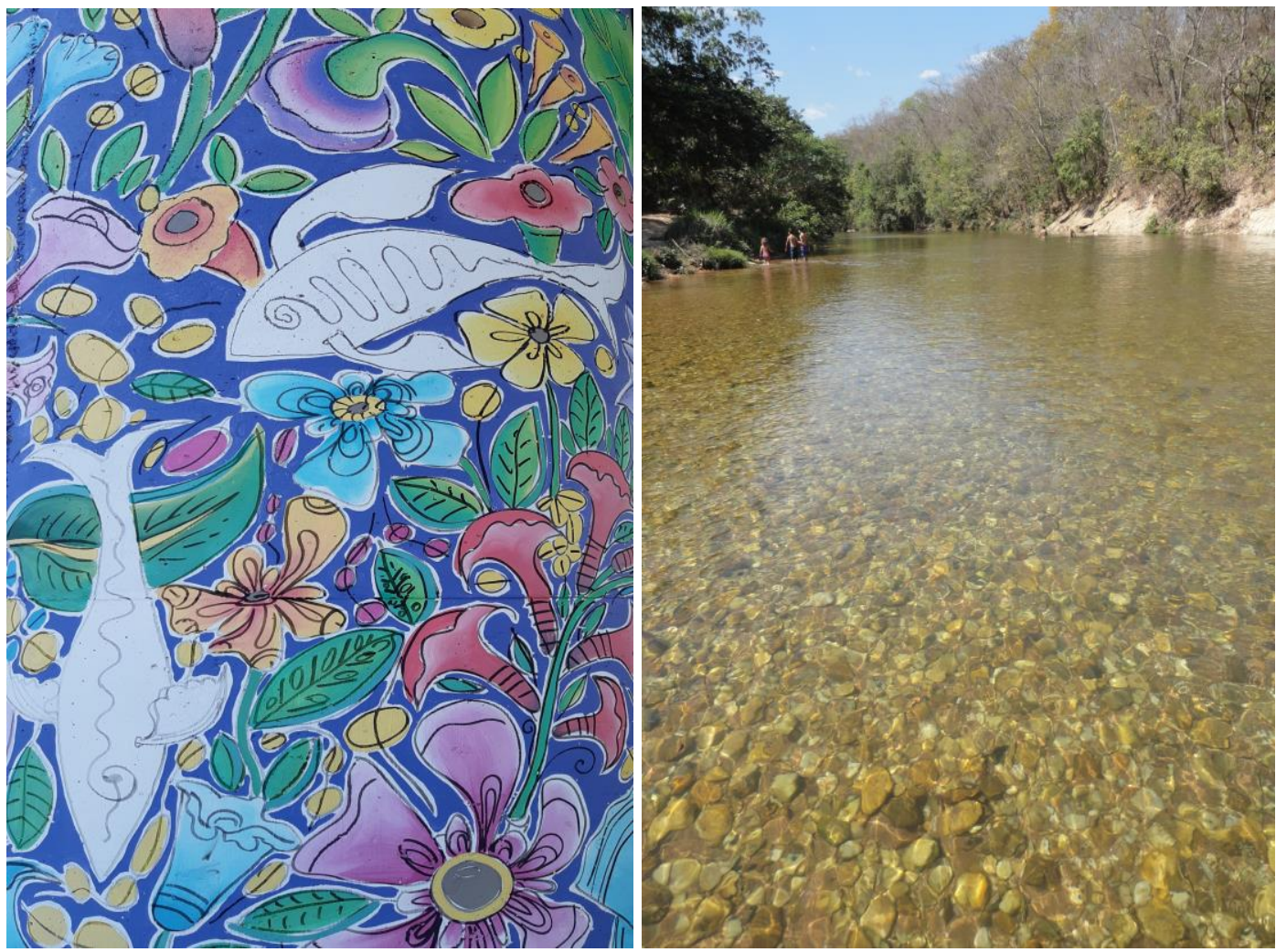

Figura 1: Peixes que "voam" em obra do artista plástico Adir Sodré em viaduto de Cuiabá Figura 2: Rio de águas limpas e transparentes que ainda correm nos arredores da cidade

O Cerrado, com seus rios de águas claras no entorno do perímetro urbano de Cuiabá, constitui referência geográfica que ganha materialidade nas artes visuais da cidade. Peixes alados e flores fabuladas atribuem cores e reinventam a paisagem urbana, marcada nas últimas décadas pela árdua e problemática experiência de metropolização. Fonte: Yuji Gushiken

Pergunta: Gostaríamos que a senhora comentasse a instituição da Educação Ambiental, como "disciplina", se assim podemos denominá-la, no campo da Educação, e também a linha de pesquisa criada no Instituto de Educação da UFMT. Qual a demanda hoje, neste ano de 2008, pela formação de professores e pesquisadores em Educação Ambiental?

Michèle Sato - Primeiro, é preciso considerar que a Educação Ambiental ( $E A)$ tem sido orientada não exatamente como uma disciplina, mas, sim, como um campo do saber. Designamos campo do saber porque partimos do princípio de que todo profissional, independente da área em que atua, trabalha a temática ambiental. Hoje, a questão ambiental envolve todo mundo.

Todo profissional, direta ou indiretamente, já atua de alguma forma com a questão ambiental. Estamos falando de Educação Ambiental nos níveis do ensino fundamental e do ensino médio. Mas há controvérsias.

Entre os pares da comunidade científica há quem considere que se cria uma disciplina, mas há quem defenda que não. Na UFMT, em Cuiabá, 
ofertamos uma disciplina chamada "Tópicos de Educação Ambiental", porque acreditamos existirem várias formas de se abordar a questão ambiental. E não há, necessariamente, uma forma que seja a única correta.

Em nosso grupo de pesquisa, na UFMT, a linha de pesquisa é em Educação Ambiental, mas há membros desenvolvendo ou que desenvolveram trabalhos sobre jornalismo ambiental, gestão ambiental, comunicação ambiental. Não se trata, necessariamente, apenas, de Educação Ambiental.

Como professora e pesquisadora, pertenço ao Instituto de Educação da Universidade Federal de Mato Grosso (IE-UFMT). Mas, antes de estar vinculada ao IE-UFMT, considero-me uma educadora, e acredito que a educação seja a mola propulsora das atividades sociais de modo geral.

A Educação Ambiental não vai resolver todos os problemas relativos ao ambiente. Entretanto, ela pode impulsionar outras áreas que, de alguma maneira, tangenciam as questões ambientais. Entre essas outras áreas, o jornalismo, por exemplo. Acredito mais precisamente no processo formativo. Mesmo que seja demorado, é mais efetivo. No jornalismo, a pauta da notícia se estabelece pelo transmissor. No processo pedagógico, estamos mais preocupados com o receptor. Para nós, a aprendizagem é mais importante do que o ensino.

Nessa perspectiva é que temos realizado várias pesquisas. Estou há mais de dez anos em Cuiabá, sempre trabalhando com pesquisa, para o que se registra uma grande demanda, não só no Brasil, mas em todo o mundo. Noto esta demanda porque trabalho com pessoas de várias faculdades e percebo o grande interesse dessas pessoas em se especializar na área ambiental, por se tratar de uma área muito abrangente e significativa.

$\mathrm{Na}$ prática de pesquisa, não nos limitamos apenas a um espaço comunitário, mas buscamos inserir a comunidade em projetos internacionais. Assim, a questão ambiental ganha uma envergadura ampla e de forma abrangente, como um guarda-chuva que acolhe diversas frentes de trabalho. Por isso é que a procura pela formação em Educação Ambiental é muito grande. Esta é uma demanda à qual fica difícil até de corresponder.

Pergunta: Com os Parâmetros Curriculares Nacionais (PCNs), de 1997, a Educação Ambiental ganhou maior evidência. No entanto, sua institucionalização se dá, como se observa nos artigos científicos da área, no "não-lugar" dos chamados "temas transversais". Quais os problemas e quais as virtudes desta condição interdisciplinar da Educação Ambiental?

Michèle Sato - O divisor de águas no Brasil para a institucionalização dos PCNs foi a ECO 92 (Conferência das Nações Unidas sobre o Meio Ambiente e o Desenvolvimento, realizada no Rio de Janeiro, em 1992). Antes dos PCNs já havia movimentos ecologistas atuando no país. 
Citamos a Rede Mato-Grossense de Educação Ambiental, que começou suas atividades em 1996, aqui no Estado de Mato Grosso, antes da institucionalização dos PCNs. Esse movimento ambientalista, que, na época, chamavam de movimento ecologista, se fortaleceu, em termos gerais, na sociedade brasileira, depois da ECO 92.

O tema da Educação Ambiental chegou, em 1997, num formato extremamente arbitrário, através de um pacote educacional do Ministério da Educação. Não foram consultadas as bases para ser instituído. Tratou-se de uma cópia das estruturas curriculares espanhola e inglesa, nas quais se versava sobre uma ideia de transversalidade.

Assim, a Educação Ambiental chegou como uma "disciplina" para que todas as áreas do conhecimento abarcassem essa dimensão ambiental, por considerar que era uma área de suma importância. Na forma como ela veio, sem discussão na base, ou seja, no nível comunitário, na escola, tornou-se um pacote, digamos assim, com o qual ninguém sabia lidar. Quando se trata de uma reivindicação da base, os movimentos sociais se organizam, e por isso sabem como lidar com o problema.

No caso dos PCNs, como a Educação Ambiental foi instituída de cima para baixo, ficou complicado de se entender. Fizeram várias tentativas, sem sucesso, e não porque foi um fracasso da escola, mas porque a escola não é uma ilha isolada de um sistema em crise.

Num ambiente de desemprego, violência e guerra, a escola sozinha não será capaz de promover o sucesso da sociedade. Portanto, quando se pergunta qual o entrave da interdisciplinaridade, ao menos aqui, na UFMT, dizemos que também não há, propriamente, interdisciplinaridade institucionalizada. Há pequenas ilhas que convergem e conversam entre si.

Tenho experiência de trabalhar com projetos interdisciplinares, seja um pequeno projeto no âmbito do Instituto de Educação, com meus colegas da área da Educação, seja no âmbito maior da UFMT, que abarca áreas como a Química e a Ecologia, até num cenário mais amplo, no qual tentamos trabalhar projetos internacionais em perspectiva interdisciplinar. Mas são poucas as experiências de sucesso. Na verdade, elas acabam se fragmentando, porque 0 pensamento cartesiano ainda impera no mundo da ciência.

Temos uma experiência com uma pesquisa feita com quinze jornalistas sobre a importância da Educação Ambiental e da dimensão ambiental no Curso de Comunicação Social. $\mathrm{Na}$ entrevista, todos responderam que Educação Ambiental não era necessária na formação deles. Neste caso, o jornalista que deseja se especializar na área precisar fazer, posteriormente à graduação, um curso de especialização. Nossa conclusão é que o próprio jornalista que produz uma notícia não está interessado no meio ambiente. Então, qual fio condutor que vai atrair as pessoas para esse tipo de jornalismo?

Tivemos um projeto aprovado na UFMT com cerca de 150 pesquisadores de várias áreas do conhecimento. Mas, normalmente, um 
projeto assim funciona como uma colcha de retalhos, em que cada pesquisador dá a sua contribuição. Nossa contribuição, na perspectiva da Educação Ambiental, é exatamente fortalecer o sistema de rede de comunicação.

Junto à Ascom (Assessoria de Comunicação) da UFMT, tínhamos um plano de promover a audiência científica e estabelecer a Rede de Comunicação Ambiental como fio condutor que pudesse traduzir as pesquisas científicas daqui para a sociedade.

Pergunta: De certa maneira, a Educação Ambiental pode ser considerada uma herdeira dos Novos Movimentos Sociais ligados à contracultura. Como essa relação política resulta na produção de um campo do saber?

Michèle Sato - Tem tudo a ver. Trata-se da produção de uma identidade. Embora eu não tenha participado dos movimentos da contracultura, o legado do movimento de resistência cultural foi impregnando minha formação pessoal. Por isso, digo que não escolhi Educação Ambiental por acaso. Tudo foi influenciado pela forma pela qual eu percebia a vida. Isto inclui a resistência ao padrão hegemônico de desenvolvimento socioeconômico.

Como consequência, minha atenção voltou-se para a busca de formas de vida alternativa, diálogos sobre alimentos orgânicos, modos alternativos de se vestir etc. Os ecologistas têm o apelido de "melancia", porque dizem que somos verdes só por fora, mas por dentro somos vermelhos, o que dá uma conotação antidesenvolvimentista, anticapitalista.

Dizem que, ao invés de fomentarmos o progresso e o desenvolvimento, queremos, na verdade, retardar este processo. Este é um marco histórico significativo no nosso grupo de pesquisa. Talvez em outros grupos não seja assim, mas aqui, na UFMT, sim. Somos um grupo de acadêmicos e fazemos pesquisas que contribuem com a ciência e a tecnologia do país, mas temos nossa resistência, nossa luta política e somos cem por cento militantes.

Estamos no campus, mas estamos também na rua. E, se precisar subir em árvores, também faremos isto. Somos produzidos por esse viés militante e ecologista, o que é muito forte em nossa formação. Não sei, na verdade, qual lado é mais forte, se o acadêmico ou o militante, mas, para nós, o importante, é, de fato, essa mistura entre as duas caracterizações.

\section{Pergunta: E qual a relação entre Educação Ambiental e os estudos de cultura?}

Michèle Sato - A Educação Ambiental, na verdade, apresenta-se como uma espécie de sinopse entre cultura e natureza. A maioria das pessoas pensa que trabalhar com Educação Ambiental significa apenas lidar com cachoeira, passarinhos etc., mas não se trata apenas disto. Nossa compreensão de Educação Ambiental traz muito da expressão cultural.

Fizemos um projeto, por exemplo, chamado "Mapa Social', que visualiza 
como, no projeto de Zoneamento Socioambiental de Mato Grosso, em debate na Assembleia Legislativa, quem são os moradores desse território.

No último relatório, identificamos 85 identidades ou grupos identitários: articuladores, assentados, atingidos por barragens, benzedeiras, ciganos, chiquitanos (povo indígena que habita o oeste de Mato Grosso e o leste da Bolívia), canoeiros, isqueiros (coletores de iscas vivas), entre outras.

Identificamos 41 etnias indígenas. A Fundação Nacional do Índio (Funai) aponta 35 e o Instituto Socioambiental (ISA), ONG que trabalha com a questão indígena, aponta 38. Nós, empiricamente, conseguimos registrar 41 grupos identitários. Todos os grupos identitários se definem pela cultura, e a cultura para essa gente está intrinsecamente associada à natureza.

Semelhante a isto, podemos citar toda a relação festiva, como as festas de santo, o cururu ${ }^{4}$ o siriri ${ }^{5}$ e outras práticas culturais. Ainda, como exemplo, no candomblé, todos os rituais se utilizam de elementos da natureza. Eles partem do princípio dos elementos da natureza (água, fogo, terra e ar).

Os princípios zen budistas são calcados também na natureza. Há princípios que, sim, são pares binários em Educação Ambiental, como cabeça e cérebro, objetividade e subjetividade, mas, em perspectiva pós-moderna, de aliança entre cultura e natureza. É nesse sentido que trabalhamos com Educação Ambiental (conferir o livro "Mapa Social: Mapeando os grupos sociais do Estado de Mato Grosso", organizado por Regina Silva e Michèle Sato, publicado em 2012, pela Editora da UFMT).

Pergunta: No seu grupo de pesquisa na UFMT, em que atuam docentes e alunos de graduação e pós-graduação, trabalha-se com uma abordagem que a senhora designa de Sociopoética da Educação Ambiental. Entre outras coisas, evidencia-se um pensamento educacional fortemente embasado na ideia de participação comunitária. Como lidar com o local e o regional, considerando as pressões do capitalismo contemporâneo sobre todos os cantos do planeta?

Michèle Sato - A Sociopoética tem, por princípio, a formação de um grupo pesquisador, fazendo sempre o trabalho de campo em grupo. Nesse contexto, não usamos mais o termo "multidisciplinaridade", porque entendemos que a disciplina é uma normativa escolar ou universitária voltada ao processo formal de construção da investigação.

Hoje, falamos em referências, porque partimos da premissa de que todo

\footnotetext{
${ }^{4}$ Roda de cantoria e dança, realizada por brincantes que tocam viola de cocho (duas vozes) e um ganzá (instrumento percussivo), muito comum nas festas de santo na região de Cuiabá, na Região Metropolitana do Vale do Rio Cuiabá (RMVRC) e na sua área de influência na Baixada Cuiabana.

${ }^{5}$ Folguedo coreografado e dançado por homens e mulheres, sendo recorrente em Cuiabá, na Região Metropolitana do Vale do Rio Cuiabá (RMRVC) e na Baixada Cuiabana.
} 
mundo tem referências. Inclusive aquela pessoa que não tem instrução formal traz uma bagagem de referências. Hoje trabalhamos com a ideia de multirreferencialidade. Essa perspectiva de pesquisa em Educação Ambiental nem sempre apresenta facilidades, porque esbarra em campos de poder, sentimentos, valores, ocorrendo muitas interferências.

Outro princípio da Sociopoética sugere trabalhar com o corpo inteiro, e não apenas com a mente. Entendemos que as emoções também são importantes. Como Paulo Freire, eu sou doutora e acadêmica, mas não tenho medo de ser amorosa. Não tenho receio de falar simultaneamente de ciência e poesia. Esses são os princípios da Sociopoética.

Trata-se de romper com um binarismo tradicional do tipo cérebrocoração, corpo-alma, preto-branco, homem-mulher, direcionando-nos para uma abordagem bem mais holística, complexa e integrada. Esse é o caminho e um princípio político do que propomos como Sociopoética da Educação Ambiental.

Pergunta: Dessa relação sociopoética, pode-se dizer que a própria Educação Ambiental se constitui como um dos vetores da crítica social às questões impostas pela modernidade?

Michèle Sato - Considero que o nosso grupo de pesquisa se encaixa mais no que chamamos de pós-modernidade, a partir de uma teoria pós-crítica, em transição e caracterizada como tal exatamente por esse mal-estar que a modernidade cristalizada, cartesiana e positivista tem causado historicamente.

No típico movimento da contracultura, de resistência, começamos a falar não só em emancipação política, mas em transformação, e usando palavras de ordem, como democracia, que faz parte da modernidade.

Transcendemos, mas também avançamos, com relação a questões de identidade, relações de gênero, mitologia, espiritualidade e várias outras temáticas esquecidas pela modernidade e que não eram aceitas como científicas. E aqui, na UFMT, temos até avançado nesse sentido.

Trabalhamos com músicos, pedagogos, biólogos, jornalistas, pessoas de várias áreas profissionais e do conhecimento, exatamente tentando fazer a recuperação desse elo indissociável entre natureza e cultura.

Pergunta: A cultura de consumo, que ganha destaque na história após a Segunda Guerra Mundial, é um item que incide diretamente na concepção de Educação Ambiental. $O$ que, nesta relação, se torna mais evidente nos dias de hoje?

Michèle Sato - A questão urbana é importante porque, cientificamente, está comprovado que os centros urbanos sempre são mais afetados, seja do ponto de vista social, da violência, do desemprego, da exclusão social, como também do saneamento, da industrialização, da poluição. 
Aqui em Mato Grosso, por exemplo, nosso maior problema ainda não é o da urbanização. Nosso maior problema é a monocultura (soja e algodão) e a derrubada de cerrados e florestas. Pode-se perceber, no Protocolo de Kyoto, que os países industrializados são os maiores responsáveis pela emissão de CO2 (dióxido de carbono, popularmente conhecido como gás carbônico). No caso do Brasil, trata-se de um país que não é uma nação rica, mas está liderando a emissão de $\mathrm{CO} 2$ pelo desmatamento e pela queimada, e nesta prática Mato Grosso é o estado "campeão".

Precisamos olhar para a cidade, mas é preciso produzir, de modo mais amplo, um olhar também para o município. Por isso, sempre tentamos fazer a proposição de Municípios Educadores Sustentáveis, e não apenas de Cidades Educadoras. Entendemos que a urbanização é importante e depende de planejamento, mas também não se deve esquecer das zonas rurais.

No caso específico de Mato Grosso, a zona rural sofre muito mais do que a zona urbana. Mas há várias formas de se trabalhar a Educação Ambiental na cidade: o planejamento físico adequado da cidade (com a questão do saneamento, que é uma das mais relevantes), o lixo como questão (coleta seletiva), tratamento de água, recursos energéticos (busca de alternativas energéticas de forma a diminuir impactos). Tudo isto, mas também considerar outras alternativas.

Coordenei um projeto chamado "UFMT Verde", com o qual gostaria de criar um planejamento físico mais consistente e alternativo (para o campus universitário), um espaço que agregasse meio ambiente e arte, reunindo artistas com várias formas de trabalho. A ideia é disponibilizar obras de arte (esculturas, pinturas) que possam dar ao campus uma identidade mais regional. Dessa forma, abriríamos espaço aos artistas da nossa região, aos nossos estudantes, e estaríamos, ao mesmo tempo, incentivando uma forma de arte ecológica. Mas o problema para implementar ações desse tipo é a falta de recursos financeiros que, em geral, são destinados apenas quando se refere ao Pantanal e à Amazônia.

Em Cuiabá seria viável realizar esta ideia, porque já há, nesta cidade, a inclinação de valorização da arte nas ruas. Percebemos que aqui alguns postes da cidade são pintados com temáticas regionais, e isto é lindo. Em algumas cidades, os postes são todos pichados. Mais arte no campus universitário seria muito agradável. 

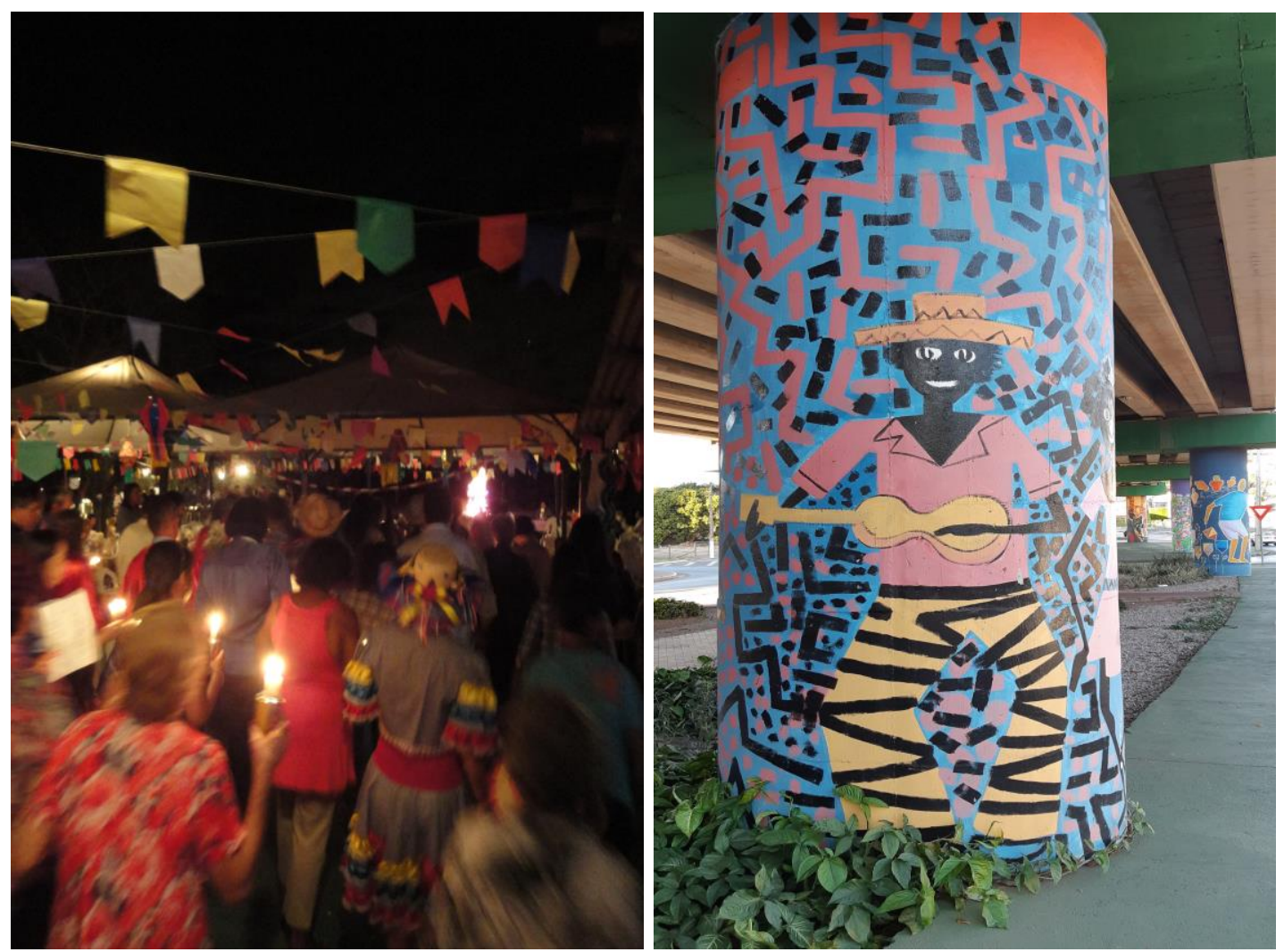

Figura 3: Festa de São João: Procissão leva imagem do santo para lavagem no rio

Figura 4: Cururueiro: Música das festas de santo traduzida para arte visual em viaduto

A lavagem da imagem de São João nas águas do rio, prática oriunda das zonas rurais, denota a relação entre cultura popular e meio ambiente. A performance do cururueiro é fixada visualmente na avenida arterial. Folclore e artes visuais no viaduto evidenciam distensão entre lugares de sociabilidade e lugares de passagem na cidade. Fonte: Yuji Gushiken

Pergunta: Em perspectiva interdisciplinar, uma das abordagens da Educação Ambiental centra-se na produção de subjetividade das populações envolvidas nos projetos. Como os saberes populares se enredam com os saberes científicos na Educação Ambiental?

Michèle Sato - De muitas maneiras, o que inclui gritos, formas de expressão, sabores e saberes. A academia possui um tipo de conhecimento validado socialmente, mas a população tem outro tipo de saber que durante muito tempo foi e continua sendo renegado e excluído. Nosso grupo de pesquisa tem tentado exatamente trazer esses conhecimentos para dentro da academia e validá-los.

Temos experiências, por exemplo, em orientar trabalhos de alunos oriundos do candomblé, orientamos trabalho sobre mitologia cigana, outro trabalho sobre mitologia Bakairi (etnia indígena que habita Mato Grosso), outro trabalho a respeito de conhecimentos populares sobre aves, fazendo cruzamento de ciência com conhecimento popular. 
O que percebemos é que não há choque entre esses conhecimentos. $O$ que há são linguagens diferentes. Possuímos, na academia, o poder da palavra, com uma linguagem sofisticada, o que pode nos diferenciar dessas pessoas, mas, em termos de compreensão, não são coisas distantes.

Pode-se fazer um entrelaçamento entre saberes, e, na verdade, temos muito a aprender com essas pessoas. $O$ aspecto bom é que aprendemos a tirar o rótulo da academia como única produtora de saberes. É claro, a academia produz saberes. Essa é a nossa primeira obrigação, mas a academia também pode aprender com os saberes de outros sujeitos.

Buscar esses saberes e validá-los no espaço acadêmico significa também respeitar essas pessoas. O caboclo que não sabe ler nem escrever sabe se vai chover ou não, porque conhece um passarinho que, quando faz o ninho mais baixo, apresenta um indício de que vai chover pouco naquela estação. Caso contrário, se faz o ninho mais alto, é porque vai chover muito.

Pergunta: Como abordar Educação Ambiental em um momento em que as atenções se voltam para o assunto, mas ainda tratado de forma bastante superficial, e até equivocada, pelos meios de comunicação?

Michèle Sato - É frustrante e decepcionante. Os próprios órgãos estatais, que deveriam fazer regulamentação, como a Secretaria de Meio Ambiente do Estado, liberam e autorizam um desmatamento muito grande. Coisas do tipo: a Famato (Federação da Agricultura e Pecuária de Mato Grosso) está instigando avanços sobre áreas do (Parque Indígena) do Xingu.

No momento em que criaram o Parque do Xingu, acredito até que não foi por má intenção dos militares, penso que foi questão de ignorar mesmo, no sentido de não saberem, que as cabeceiras dos rios estão todas fora do Xingu. Qualquer cientista sabe que, danificando-se a cabeceira, danifica-se todo o rio. Portanto, é necessário proteger aquela área, e nós, ecologistas, estamos lutando para que aquela área seja protegida, mas a entidade da agricultura e da pecuária quer avançar com soja, agrotóxico, monocultura.

Tudo isto é difícil e revoltante. Ao mesmo tempo, a Educação Ambiental precisa de estudo profundo na área de Psicologia, porque, nessas disputas, a impressão é que estamos sempre perdendo. Em contrapartida, nunca vi um grupo mais esperançoso do que o de educadores ambientais. Ele perde, toma "porrada", vai para a rua xingar, volta para casa derrotado. Mas, no dia seguinte, ele se levanta e vai para a batalha, novamente.

Trata-se de uma incansável luta. Mas isto, na verdade, faz parte de nossa herança cultural. Não queremos ganhar. Queremos é lutar. É provável que a gente perca. Assim também como é provável que esse planeta um dia exploda. E, quem sabe, no futuro, vão se lembrar que no passado havia uns primitivos visionários falando sobre meio ambiente o tempo todo. Quem sabe vão reconhecer nosso esforço. Mas, na verdade, não estamos torcendo por isso. Só queremos mostrar de que lado estamos.

revista brasileira educação ambiental 
Pergunta: Quais são, atualmente, os desafios epistemológicos da Educação Ambiental?

Michèle Sato - Primeiro, a Educação Ambiental faz parte do movimento de contracultura, e por isso significa luta contra uma verdade hegemônica. Mas nem por isto se pretende fixar discursivamente o que é certo ou errado. Nosso grupo de pesquisa (Gepea-UFMT) tem uma forma de atuar e compreender Educação Ambiental, que não é a única e nem é apenas ela a única verdadeira, sabemos disto.

Em nosso percurso, podemos nos deparar com pessoas que, pelo simples ato de abraçarem árvore, asseguram que estão fazendo Educação Ambiental. Noventa por centro das pessoas no Brasil dizem, por exemplo, que coleta seletiva é Educação Ambiental. Outros chamam um especialista para fazer palestra no dia 05 de junho, Dia Internacional do Meio Ambiente, e dizem que isto é Educação Ambiental. Para mim, não é. Ainda falta muito.

Entendo que Educação Ambiental é uma tática que usamos para mudar o mundo, que é injusto do ponto de vista socioambiental. Abraçar árvore não vai mudar o mundo. É legal e faz bem para a alma, e, então, por isso, acreditamos que existem várias formas de Educação Ambiental. Partindo desse princípio, não conseguimos e nem queremos definir conceitualmente Educação Ambiental, porque acreditamos que Educação Ambiental se traduz num olhar fenomenológico, e depende de quem a está olhando.

Mas, por conta disso, a abertura conceitual tem duas faces: há a beleza da liberdade, mas há também a face que inclui "qualquer coisa". Por isso, defendemos que é necessário realizar mais pesquisas e publicar mais artigos, para mostrar que Educação Ambiental é mais do que abraçar árvores. Esse é o nosso maior desafio em instância teórica e epistemológica.

Pergunta: Pelo que se observa nos estudos desenvolvidos na UFMT, a Educação Ambiental é considerada uma rede de fluxos e troca de informações. Dada a complexidade de se planejar Educação Ambiental nesse formato, como se avaliam projetos nessa amplitude?

Michèle Sato - A avaliação é uma tarefa complexa para todo educador. E nós ainda não conseguimos sair muito do modelo tradicional de avaliação. $O$ doutorado, por exemplo, é constituído de provas e títulos. Já os projetos e produções científicas têm duas formas de avaliar os fluxos e refluxos da academia. Há o modelo tradicional, no qual se tem objetivo, método utilizado e que resultado se obtém. Há também outro modelo de avaliação, um modelo naturalista, que não tem nada a ver com natureza, mas no qual se avalia o processo de construção do conhecimento.

$\mathrm{E}$ algumas vezes, determinados projetos não conseguem alcançar os resultados propostos, devido ao processo no qual foi conduzido. Neste caso, desenvolver processos torna-se mais relevante do que alcançar um resultado. O ideal, talvez, seja mesclar estas duas abordagens. 
O modelo tradicional de projeto - com princípio, meio e fim - também deve considerar uma avaliação mais subjetiva, ou seja, avaliar o processo de produção de conhecimento. A nosso ver, a avaliação em Educação Ambiental se insere mais no desenvolvimento de processos.

Para nós, o mais importante é considerar o processo: "o que fazer", "para quem fazer", "como fazer". Importante é a construção de um processo educacional. Mas, no contexto acadêmico, é mais fácil fazer projeto já visando divulgação dos resultados, por se tratar de produção científica, em forma de livro, artigo, resumo, site.

Mas, além dessas modalidades de divulgação científica, ainda há outras formas de divulgação, para outros públicos. Em nosso grupo de pesquisa, fizemos um material pedagógico elaborado com pessoas do Quilombo de Mata Cavalo (localizado no município de Nossa Senhora do Livramento, na Região Metropolitana do Vale do Rio Cuiabá, a 27 km de Várzea Grande e Cuiabá).

Trata-se de um material com linguagem mais simples, que utiliza técnicas comunicacionais, feito de modo interativo com pessoas da comunidade. Estas são variáveis que não contam pontos no Currículo Lattes. Mas a beleza da Educação Ambiental está justamente no fato de sermos mais do que acadêmicos: sermos, também, militantes. E nós partimos do princípio de que a comunidade é que está fazendo História.

\section{Pergunta: Depois do amadurecimento das experiências em Educação Ambiental, faz sentido conceber nuances entre a atribuição ou missão deste campo do saber de se produzir uma subjetividade que transita entre "consciência ecológica" e "sensibilização ambiental"?}

Michèle Sato - Primeiro, é preciso eliminar o mal-estar de que o termo "ecologia" transcendeu da ciência, porque, na verdade, ele foi apropriado por diversas áreas do conhecimento. O próprio movimento ecologista difere da ciência e da Ecologia porque consciência ecológica e sensibilidade ambiental diferem uma da outra, em alguns aspectos. Por exemplo, hoje em dia, dificilmente alguém diria que o ambiente não é uma questão importante.

Ouvimos o tempo todo o governador, o presidente, a reitora falando em desenvolvimento sustentável, e também as ONGs, os estudantes, enfim. Será que não há uma diferença? A Famato (Federação de Agricultura e Pecuária do Estado de Mato Grosso), por exemplo, diz que é "ambientalista". Ela tem um departamento responsável por "cuidar" do tema meio ambiente. Precisamos, portanto, primeiramente definir o que é ecologismo e o que é ambientalismo.

Ambientalismo, em minha opinião, emerge na década de 1980 e institui, nos termos do desenvolvimento sustentável, um relatório do nosso futuro comum. Já o ecologismo é um movimento que vem da década de 1960, dos movimentos de contracultura, e não fala em desenvolvimento sustentável, mas, sim, em sociedade sustentável. Embora a pauta inclua economia em seu repertório, ela não se sobressai, pois a sociedade está em primeiro lugar. 
Anos depois, a partir de 1987, é que começa a emergir essa luta de resistência. Portanto, na verdade, nosso legado, quando se diz que a contracultura produziu um efeito bastante forte em nós, foi esta definição. Hoje nós, como ecologistas, até mesmo para marcar uma posição crítica, precisamos nos distinguir.

Se a Famato é ambientalista e se o Blairo Maggi (produtor de soja, empresário e, na época da entrevista, governador do Estado de Mato Grosso) é ambientalista, então nós não somos ambientalistas. Somos ecologistas. É por este motivo que a concepção de ecologia é eminentemente política, de se pretender transformar o mundo.

Assim, não estamos interessados apenas em fazer uma sensibilização ambiental, até porque acreditamos que a sociedade já está sensibilizada. Hoje em dia, todos professam que o meio ambiente é importante, mas a ação das pessoas muda porque o estilo desenvolvimentista que a sociedade impõe faz com que elas queiram ganhar dinheiro. Por isso, mais do que sensibilização ambiental, acreditamos em transformação e emancipação ecologista.

Pergunta: Nessa mesma linha de questionamento, gostaríamos de perguntar sobre a relação entre educador e população envolvida. Por que, no campo da Educação Ambiental, se fala na diferença entre "habilitação pedagógica" e "formação do sujeito ecológico"?

Michèle Sato - O sujeito ecológico é concebido como um sujeito ideal, numa perspectiva que compreende haver sistema elétrico com luz solar, fontes alternativas de energia, hábito por comida orgânica, utilização de combustível alternativo, reciclagem de papel etc.

A profissionalização vem na formação do sujeito de modo formal, ou seja, na formação escolarizada. Uma formação está no âmbito mais individual do sujeito. Outra, no âmbito mais institucional do organismo que vai promover a formação, a habilitação do indivíduo. O sujeito ecológico está centrado na premissa do eu, ou seja, no que cada um entende como mundo. Ou, ainda, o que o mundo representa para cada um.

Pergunta: Como a Educação Ambiental se replica hoje nos níveis de ensino médio e fundamental? Seria conveniente haver estudos de caso para demostrar a paisagem educacional que se desenhou nesses anos de experiência em Educação Ambiental?

Michèle Sato - Também, mas não apenas isto, porque, além de mostrar estes estudos de caso, é preciso também criar novas situações educacionais. E só se consegue criar novas situações quando se faz pesquisa. Nesse caso, trata-se de fomentar a pesquisa.

Temos, por exemplo, estudo de caso, em uma dissertação de mestrado, 
de fazer com que a escola não se isole do lugar em que está localizada, mas que, ao contrário, atue junto à comunidade.

Mas não se trata daquele discurso, típico reflexo do neoliberalismo, de meramente chamar a comunidade para fazer mutirão de limpeza e pintar o prédio, trocar cadeado do portão. É o contrário: fazer a escola sair de seus muros e envolver-se mais com a comunidade de seu entorno. Para isto, não é necessário pesquisa acadêmica ou pesquisa científica, como fazemos na universidade, porém, mais projetos de intervenção social.

Trata-se, por exemplo, de fazer pesquisas de exploração, mais rápidas, com o objetivo de produzir significados, sentidos. Outro exemplo: convidar, para participar de um projeto, um morador antigo de um bairro, e fazer um reconhecimento do que mudou naquele ambiente. Quantas árvores havia? Aumentaram os estabelecimentos residenciais e comerciais? Que benefícios foram conquistados?

Podemos fazer este tipo de construção científica em uma escola, com o detalhe de fazê-lo em parceria com a comunidade. Muitas vezes, essa comunidade tem propostas que podem interagir através, entre outras instâncias, das associações de bairros. As alternativas devem ser pensadas, não de forma equivocada, mas de modo eficaz.

\section{Pergunta: Como a senhora avalia a contribuição da institucionalização do Doutorado em Educação na UFMT para a formação de pesquisadores?}

Michèle Sato - O curso de doutorado foi um sonho buscado aqui na UFMT. Já tínhamos a experiência de construir o primeiro curso de mestrado no âmbito desta instituição, e depois conseguimos abrir vagas para o nível do doutorado. Em perspectiva acadêmica, o doutorado permite gerar muito mais conhecimentos, além de sermos mais reconhecidos.

Haverá mais significado epistêmico, e este conhecimento produzido pode contribuir para a geração de políticas públicas. Do ponto de vista de uma professora que está aqui dentro da universidade, significa também reconhecimento das autoridades. No caso, as do Ministério da Educação.

\section{Pergunta: Defina o que é, para a senhora, Educação Ambiental e como avalia a importância desse campo do conhecimento.}

Michèle Sato - Para mim, trata-se de ressignificar a minha existência. Não sou educadora ambiental, como se fosse uma profissão, mas esta é a minha identidade profissional. Esta identidade, na construção da Educação Ambiental, implica compreender que natureza e cultura são dois elementos que não podem ser separados.

Para se falar em proteção ao mico-leão-dourado, é preciso falar em proteção ao menino de rua, porque os problemas coexistem. Também não há como tratar primeiro do social e depois cuidar do meio ambiente. É aí que está 
o desafio, porque normalmente os campos dos saberes têm focos muito bem delineados e agem de modo específico.

No caso da Educação Ambiental, o campo é muito abrangente, e por isso torna-se mais difícil lidar com ele. Mas também não temos uma visão utilitarista para resolução de problemas. Não partimos da premissa de que o conhecimento tem que resolver problemas, mas ele deve ser produzido, elaborado em benefício da humanidade.

A ideia de nos responsabilizarmos para resolver todos os problemas seria uma carga muito pesada, e não só para a Educação Ambiental, mas para qualquer área do conhecimento. No entanto, fazer com que todos se despertem para falar de Educação Ambiental já seria um resultado a se registrar, porque assim ela se fortalece.

Percebemos que a ciência, vista pelo ângulo da utilidade, não tem servido muito para resolver problemas. Talvez seja o caso de repensar formas de produzir conhecimento e recuperar sentimentos, espiritualidades, desejos, esperanças, utopias.

Numa pesquisa realizada na UFMT, quando perguntamos aos alunos 0 que era qualidade de vida, tivemos um resultado frustrante. Entre todas as respostas, não havia nenhuma que pedisse um mundo mais justo, com menos impactos, menos injustiças. Isto foi lamentável, porque nosso desejo é realmente o de melhorar o mundo.

Diante disto é que seguimos devagar, e sem uma revolução ruidosa. Ao contrário, Educação Ambiental é morosa, mas esperançosa. Aliás, se fosse

para resumir Educação Ambiental em uma palavra, esta palavra seria "esperança".

\section{Agradecimentos}

Agradecemos à Profa. Dra. Michèle Sato, líder do Grupo Pesquisador em Educação Ambiental, Comunicação e Arte da Universidade Federal de Mato Grosso (Gepea-UFMT/Cuiabá), pela leitura da versão transcrita e editada do texto e por autorizar a publicação da entrevista após doze anos de sua realização. 